\title{
Synthesis and key characteristics of nanocrystalline AlCuNiFeCr high-entropy alloy by MA and sintering
}

\author{
A. Yurkova, V. Chernyavsky, D. Hushchyk \\ Department of High Temperature Materials \\ National Technical University of Ukraine "Igor Sikorsky Kyiv Polytechnic Institute" \\ Kyiv, Ukraine \\ yurkova2403@gmai.com; vadikv13@gmail.com; dima94g@ukr.net
}

\begin{abstract}
The present study is primary addressed to structural evolution of multi-component AlCoNiFeCr highentropy alloy (HEA) from elemental materials to solid solution during mechanical alloying (MA), and further, to equilibrium phases during subsequent thermal annealing and pressure sintering. It was justified experimentally that MA of Al-Cu-NiFe-Cr powder mixture during 5 hours resulted in a single-phase nanocrystalline HEA with a structure of BCC solid solution. During thermal annealing recovery and recrystallization of the BCC solid solution take place at temperatures ranging from 130 to $500{ }^{\circ} \mathrm{C}$, and phase transformation, and grain growth of equilibrium phases occur at higher temperatures. The phase composition transforms to $\mathrm{BCC}$ and FCC solid solutions when the MA powder was annealed at $600{ }^{\circ} \mathrm{C}$ for $1 \mathrm{~h}$. The $\mathrm{BCC}$ and FCC solid solution structure can be maintained even after the alloy was annealed at $1000{ }^{\circ} \mathrm{C}$. The alloy powder was consolidated by pressure sintering at $800{ }^{\circ} \mathrm{C}$ with $5 \mathrm{GPa}$ pressure for half an hour. The sintered samples exhibit $9.2 \pm 0.3 \mathrm{GPa}$ in Vickers hardness.
\end{abstract}

Keywords - high-entropy alloy; mechanical alloying, nanostructure; thermal stability; mechanical properties

\section{INTRODUCTION}

The first results on multi-component and high entropy alloys were published in 2004 [1,2], about 14 years ago. Highentropy alloys (HEAs) are a promising class of alloys which are designed based on the use of multiple component alloying elements in equimolar or near equimolar ratio and could have a broad range of compositions, phases, and microstructures and thus create a wide range of physical, mechanical, and chemical properties $[3,4]$. There has been surging interest in this class of alloys on account of their unique property range. These alloys, in sharp contrast to traditional alloys based on one or two principal elements have one exceptional characteristic: the unusually high entropy of mixing. Some core effects in HEAs would be more pronounced than those in conventional alloys [1-4]: high entropy - it enhances the formation of simple solid solution phases, such as BCC and/or FCC structures, and thus simplifies the microstructures; severe lattice distortion - it arises from the atomic size difference among different elements in solid solution phases and might markedly influence mechanical, physical and chemical properties; sluggish diffusion - it is due to the inefficient cooperative diffusion of various species and thus slow down

This work was supported by Ministry of Education and Science of Ukraine [project \# 2106] phase transformations; and cocktail - it comes from the ideal mixing and inevitably excess interactions among the multiprincipal elements in solid solution phases, and thus is a composite effect on properties. HEAs are known to have good thermal stability, high hardness, strength, excellent wear resistance, excellent balance between high strength and sufficient ductility and impressive corrosion resistance $[3,4]$. Some of these spectrums of properties are rarely observed in conventional alloys, making HEAs attractive in many fields. For instance, superior structural alloys are in high demand for extreme and highly sensitive engineering service environments, particularly in the nuclear, turbine, and aerospace industries. The properties of HEAs make them suitable candidates for use in such environments

For fabricating HEAs, three main routes are also applied: ingot metallurgy, powder metallurgy, and coating and deposition. Mechanical alloying (MA) is a widely used highenergy solid state processing route for the synthesis of advanced materials [5]. The extension of solid solubility with good homogeneity and room-temperature processing are the main advantages of MA over the casting route associated with segregation and inhomogeneity, especially with multicomponent systems with large differences in the melting points. Further, MA route is also established to facilitate the formation of nanocrystalline HEA. In this paper, the $\mathrm{AlCuNiFeCr}$ HEA powder was prepared by MA and as-milled powder was consolidated by pressure sintering and the structure and mechanical properties were investigated.

\section{EXPEROMENTAL}

\section{A. Materials and Processing}

Equiatomic elemental blend of $\mathrm{Al}, \mathrm{Cu}, \mathrm{Ni}, \mathrm{Fe}, \mathrm{Cr}$ powders with purity higher than $99.8 \%$ and particle size of $\leq 50 \mu \mathrm{m}$ was mechanically alloyed to synthesize quinary equiatomic $\mathrm{AlCuNiFeCr} \mathrm{HEA}$. The milling of elemental powders was carried out up to $5 \mathrm{~h}$ in high energy planetary ball mill at $580 \mathrm{rpm}$ with ball to powder weight ratio of 10:1. Hardened steel vial and balls were used as a grinding media and petrol was used as a process controlling agent. The powder samples were extracted at intervals of $0.5,1,2$, and $5 \mathrm{~h}$ during milling. The $5 \mathrm{~h}$ ball milled alloy powder was then heat treated $1 \mathrm{~h}$ at different temperatures $\left(500 ; 600 ; 700 ; 800 ; 900 ; 1000{ }^{\circ} \mathrm{C}\right)$ under flowing high purity argon atmosphere. Then, ball milled 
alloy powder was consolidated by pressure sintering at $800{ }^{\circ} \mathrm{C}$ with $5 \mathrm{GPa}$ pressure for $0.5 \mathrm{~h}$.

\section{B. Structural Characterisation}

The effects of milling duration $(0.5,1,2,5 \mathrm{~h})$, subsequent annealing at temperatures ranging from 500 to $1000{ }^{\circ} \mathrm{C}$ and consolidation of as-MA alloy on the structure and phase transformation were investigated by means of Rigaku Ultima IV X-ray diffractometer (XRD) with $\mathrm{Cu} \mathrm{K \alpha}$ radiation. The crystallite size in the milled powders as well as after annealing and consolidation has been calculated from the XRD peak broadening using peak profile analysis after eliminating the instrumental and strain contributions. A scanning electron microscope (SEM) equipped with an energy dispersive spectrometer (EDS) was used to obtain basic information concerning microstructural features and measure the chemical composition of materials. The thermal analysis in the temperature range of $30-1430^{\circ} \mathrm{C}$ was carried out in a STA449F1 Jupiter differential scanning calorimeter (DSC) at a heating rate of $20 \mathrm{~K} / \mathrm{min}$ under flowing purified argon atmosphere.

\section{Mechanical Testing}

Microhardness measurements were performed using a conventional microhardness machine equipped by standard Vickers' pyramid. Microhardness numbers were determined under indentation loads not higher than $1.5 \mathrm{~N}$. Loaddisplacement measurements were fulfilled to determine Young's modulus, E, according to the test method procedure proposed by Oliver and Pharr [6].

\section{RESULTS AND DISCUSSION}

\section{A. Structure evolution of elemental powders during MA}

Fig. 1 shows the XRD patterns of the equiatomic AlCuNiFeTi MA powders prepared under different milling times. The pattern of $0 \mathrm{~h}$ exhibits peaks of all the pure elements in the initial mixture (blend). It can be seen that as milling time increases, drastic decrement of diffraction intensity and peak broadening are observed. The peak intensity decreases dramatically in the early stages of milling after the powder was grinded for $0.5 \mathrm{~h}$. Obvious peak broadening can be observed and a lot of peaks become invisible as the alloy powder was milled for $1 \mathrm{~h}$. The disappearance of diffraction peaks can be seen as the beginning of the solid solution formation. Only the most intense diffraction peaks can be clearly seen in the $2 \mathrm{~h}$ ball milled powder, which indicates the complete formation of the single phase solid solution with bcc structures ( $\beta$-phase).

As the milling time reaches up to $5 \mathrm{~h}$, the diffraction peaks exhibit no change except for a minor broadening. The intensity decrement and peak broadening in the diffraction can be attributed to the formation of nanocrystalline and high lattice strain induced by severe plastic deformation during the MA processing [7]. However, the cause of diffraction peak disappearance is complicated, which can be introduced by particle and crystal refinement together with high lattice strain, different atomic diffraction factor proportional to the atomic number, crystallinity decrement, formation of solid solution.
For the XRD peak intensity, the distorted atomic planes increase X-ray diffuse scattering effect and give smaller peak intensity [7]. Most of the diffraction peaks can hardly be seen after be ball milled for $2 \mathrm{~h}$. Thus, the formation of nanocrystalline and high lattice strain are primary factors of the above-mentioned broadening and decrement of diffraction intensity of the diffraction peaks. Moreover, size mismatch effect between the constituents, increasing grain boundary fraction and increasing dislocation density produced by severe plastic deformation lead to the increment of lattice strain [7].

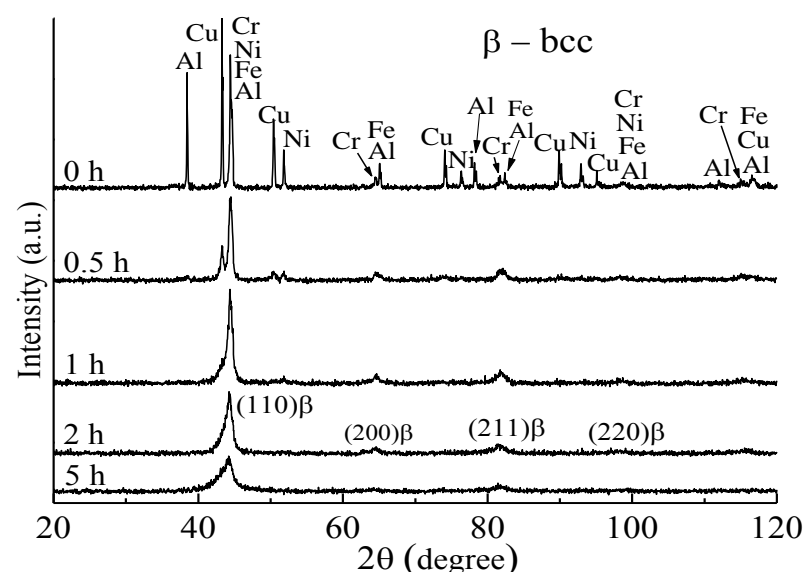

Fig. 1. XRD patterns of $\mathrm{AlCuNiFeCr}$ powders with different milling times

The crystal size of the alloy powders under different milling times have been calculated from the X-ray peak broadening using Scherrer's formula after eliminating the instrumental contribution. The crystallite size of the alloy powders after $2 \mathrm{~h}$ of milling was nearly $50 \mathrm{~nm}$. After $5 \mathrm{~h}$ of milling the crystallite size reduced below $20 \mathrm{~nm}$. The crystal structure of the nanocrystalline AlCuNiFeCr HEA is identified as bcc with lattice parameter $a=0,2893 \mathrm{~nm}$.

It is known that most of the binary metallic systems in the $\mathrm{AlCuNiFeCr} \mathrm{HEA}$ system possess limited solid solubility under equilibrium condition because of their positive heats of mixing. However, the five components MA powders with milling duration higher than $1 \mathrm{~h}$ show simple solid solution structure, which can be attributed to the formation of supersaturated solid solution. The solid solubility extension is introduced by the effect of high mixing entropy and the nonequilibrium state of the MA process. As the component number increases, the random diffusion between different elements will be enhanced and thus the solid solubility is extended. In addition, the high-entropy of mixing can lower the tendency to order and segregate, and therefore makes the solid solution more easily formed and more stable than intermetallics and other ordered phases $[3,4]$. On the other hand, the MA process can also extend the solid solubility limits [5]. Alloying occurs when the grain sizes of the elemental components decrease down to nanoscale and then a substantial amount of enthalpy can be stored in nanocrystalline alloy due to the large grain boundary area. The energy stored in the grain boundaries serves as the driving force for the formation of solid solution [7]. Interdiffusion among the components occurs and the solid solubility is expected to increase with milling time increasing until it 
reaches a supersaturation level, beyond which no further extension of solid solubility will be achieved [5].

The entropy of fusion of all the elements in the present system is less than that of the configurational entropy of the five-component system $\left(\Delta \mathrm{S}_{\text {mix }}=13.38 \mathrm{~J} \cdot \mathrm{mol}^{-1} \cdot \mathrm{K}^{-1}\right)$, which means the randomness due to the number of elements present in the system is higher than the randomness in the melting. This high configurational entropy and also the large quantity of defects induced during MA process may lead to the formation of simple crystal structure in this HEA. The formation of amorphous phase at the equiatomic composition in the present system is not observed, possibly due to the smaller differences in the atomic sizes $(\delta=4.9 \%)$.

\section{B. Microstructure and Chemical Composition Characterization}

The primitive powder exhibits a granular size of less than $50 \mu \mathrm{m}$. It's known that the ball to powder interaction during high-energy ball milling involves continuous plastic deformation, fracture, and welding of particles finally leading to the nanocrystallization or even amorphization [5]. In the early period of MA process the particles firstly cold weld together to form even larger particles. The cold welded agglomerations are crushed down to smaller particles when the milling is prolonged. This circulation leads the powder be refined gradually and facilitates the diffusion and alloying among different metallic elements. Equilibrium between the crushing and fragmentation is achieved at $5 \mathrm{~h}$ milling duration. The $5 \mathrm{~h}$ ball milled alloy powder shows refined morphology with average particle size of $14 \mu \mathrm{m}$ as shown in Fig. 2. The quantitative elemental microanalysis results from the EDX spectrum (not listed in this paper) clearly indicates that the homogeneity and the equiatomic composition is maintained in each particle of the alloy after $5 \mathrm{~h}$ of MA.

\section{Structural stability of MA AlCuNiFeCr high-entropy alloy}

Fig. 3 depicts the differential scanning calorimetry (DSC) curve of the $5 \mathrm{~h}$ mechanically alloyed $\mathrm{AlCuNiFeCr}$ highentropy powder. The $5 \mathrm{~h}$ MA powder exhibits exothermic /endothermic trends in the temperature range of $30-1400{ }^{\circ} \mathrm{C}$. The endothermic peak at $95.6^{\circ} \mathrm{C}$ is associated with energy absorption. This energy absorption can be related to the evaporation of process controlling agent (PCA) and gas. The long exothermic line in the temperature range of 130 to $350{ }^{\circ} \mathrm{C}$ and the broad exothermic peak with maximum at $450{ }^{\circ} \mathrm{C}$ in the DSC curve are associated with the release of internal stresses, such as structural deformation, lattice strain, etc. The exothermic peak at $575{ }^{\circ} \mathrm{C}$ is related to the energy release during the phase transformation process. The exothermic peak in the temperature range of $750{ }^{\circ} \mathrm{C}$ to $1075{ }^{\circ} \mathrm{C}$ can be attributed to the recrystallization of the BCC and FCC solid solutions. After heating to $1160{ }^{\circ} \mathrm{C}$, an endothermic curve appears and it can be attributed to the gradual collapse of crystalline structure under high temperature. An endothermic peak appears at $1229^{\circ} \mathrm{C}$, indicating the beginning of melting. The endothermic peak at $1310{ }^{\circ} \mathrm{C}$ is designated as the alloy melting point.
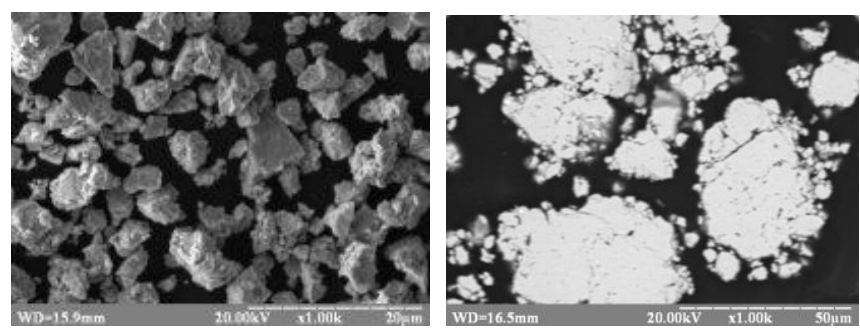

Fig. 2. SEM images of AlCuNiFeCr high-entropy alloy powder under $5 \mathrm{~h}$ milling durations

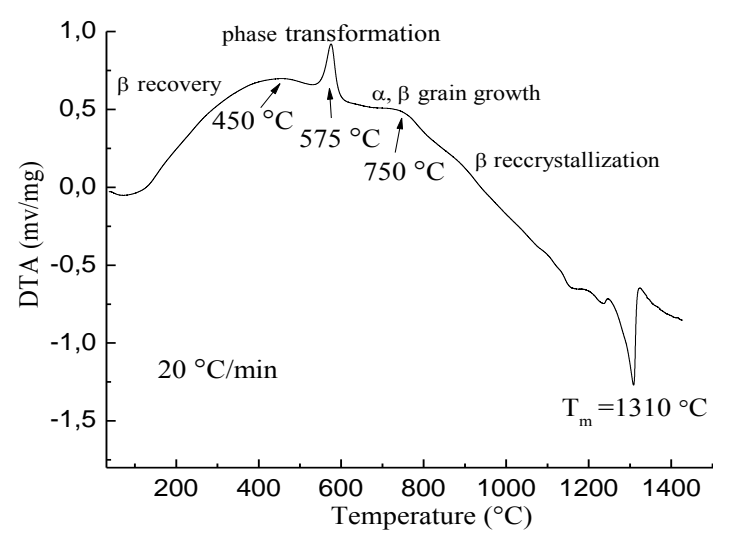

Fig. 3. DSC runs for the $5 \mathrm{~h}$ MA AlCuNiFeCr high-entropy alloy powder

The $5 \mathrm{~h}$ MA AlCuNiFeCr HEA powder was annealed $1 \mathrm{~h}$ at different temperatures and their XRD patterns are shown in Fig. 4. The XRD patterns of the MA $\mathrm{AlCuNiFeCr}$ powders after thermal annealing at 500 and $600{ }^{\circ} \mathrm{C}$ in Fig. 4 reveals that long exothermic curve and the broad exothermic peak at $400{ }^{\circ} \mathrm{C}$ in the DSC curve represents the recovery of the $\beta$ phase with stress releases. This is because the $500{ }^{\circ} \mathrm{C}$ and $600{ }^{\circ} \mathrm{C}$-annealed XRD patterns in Fig. 4 show that the broad peaks (110) and (211) of the $\beta$-phase become sharper. This represents a bcc solid solution ( $\beta$-phase) with fine grains of about 30-35 $\mathrm{nm}$ in diameter.

Fig. 4 reveals that after annealing at $500{ }^{\circ} \mathrm{C}$, the XRD pattern exhibits fcc peaks along with original bcc peaks. This indicates the phase transformation, which corresponds to the sharp exothermic peak at $575{ }^{\circ} \mathrm{C}$ in the DSC curve. After annealing at $600{ }^{\circ} \mathrm{C}$ there is another fcc 1 phase precipitates beside the main fcc solid solution at the same time. Fig. 4 indicates that after annealing at 800,900 and $1000{ }^{\circ} \mathrm{C}$, the powders exhibit both bcc and fcc mixed phases. However, the major phase transforms to the fcc structure while the bcc phase shows as the minor phase when it is annealed at $1000{ }^{\circ} \mathrm{C}$. The increasing of XRD peak intensities of the bcc and fcc phases results from the crystal coarsening and internal energy release during the annealing process and corresponds to the broad exothermic line in the temperature range of $700-1000{ }^{\circ} \mathrm{C}$ in the DSC curve. 
The phase transformation under annealing temperatures can be attributed to the metastable state of the supersaturated bcc solid solution [8]. This metastable structure transforms to stable equilibrium phases in the final stage of annealing.

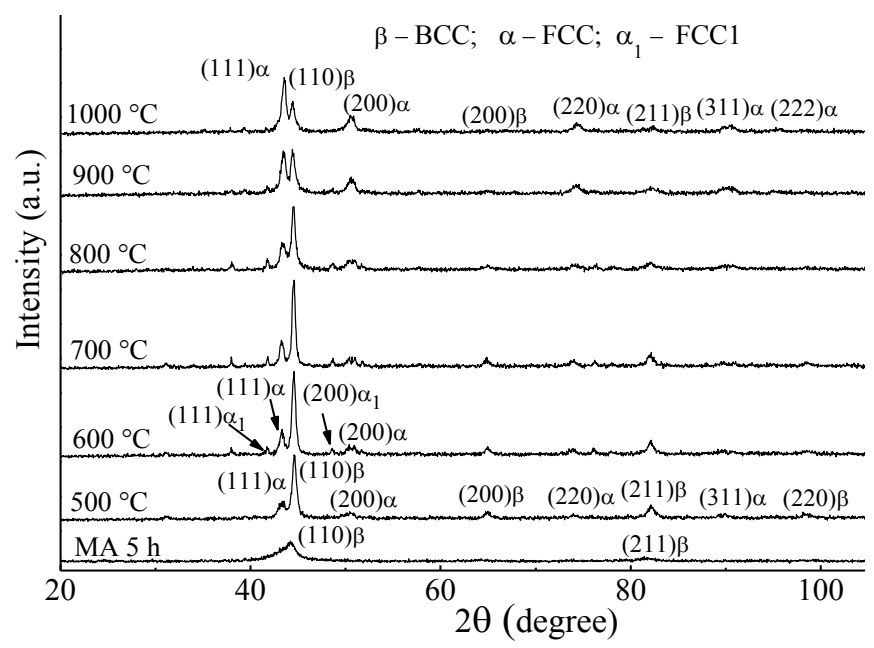

Fig. 4. XRD patterns of $\mathrm{AlCuNiFeCr}$ high-entropy alloy resulted from mechanical alloying and after thermal annealing at different temperatures

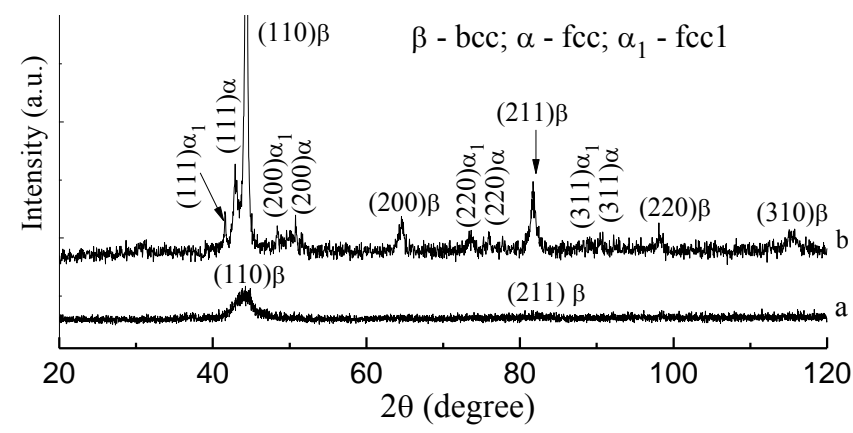

Fig. 5. .XRD patterns of equiatomic AlCuNiFeCr HEA after MA (a) and asconsolidated at $800{ }^{\circ} \mathrm{C}$ with $5 \mathrm{GPa}$ pressure for $0.5 \mathrm{~h}$ (b)

Both as-milled and as-annealed $\mathrm{AlCuNiFeCr}$ high-entropy alloy powders show simple solid solution structure, which indicates the successful synthesis of high-entropy solid solution alloy powder by mechanical alloying.

\section{Sintering under pressure of MA AlCuNiFeCr high-entropy alloy}

The XRD patterns (shown in Fig. 5) reveal that the sintered bulky sample is consisted of simple solid solution structure, which is the same as that of the $800{ }^{\circ} \mathrm{C}$ annealed alloy powder. The XRD pattern confirms that the asconsolidated alloy is composed of major bec phase and the small volume fraction of two fcc phases. Obvious peak broadening, shown in Fig. 5b, confirm the nanocrystalline nature of $\mathrm{AlCuNiFeCr}$ HEA with bcc and fcc structure. The crystallite size of the main bcc phase of the alloy is $90 \mathrm{~nm}$ and the lattice parameters of the phases present in the alloy are $0.2878 \mathrm{~nm}$ for bcc, $0.3617 \mathrm{~nm}$ for fcc, respectively.

SEM micrograph of bulk specimen is shown in Fig. 6, which reveals the presence of three phases. The SEM-EDX results are given in Table, which gives the compositions of the each phase present in the alloy. Grey phase (1 in Fig.6) has all the five elements and is rich in $\mathrm{Al}, \mathrm{Fe}$ and $\mathrm{Cr}$ and depleted in $\mathrm{Cu}$ and Ni. Light grey and white phases (2 and 3 in Fig. 6) are rich in $\mathrm{Cu}$ and $\mathrm{Ni}$, and depleted in $\mathrm{Al}, \mathrm{Fe}$ and $\mathrm{Cr}$. From the volume fractions of the phases, it appears that the grey coloured phase is the bcc one and the other two ones are the fcc and fcc1 phases.

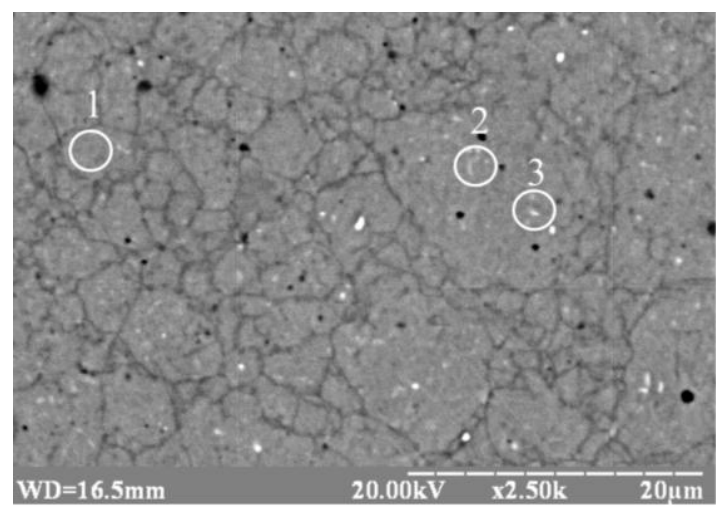

Fig. 6. SEM image of AlCuNiFeCr high-entropy alloy after sintering under pressure $5 \mathrm{GPa}$

TABLE CHEMicAl COMPOSITION OF PHASES IN THE AlCuNiFeCr HEA AFTER PRESSURE SINTERING

\begin{tabular}{|c|c|c|c|c|c|}
\hline Phase & Al & Cu & Fe & Ni & Cr \\
\hline Bulk & 19,6 & 19,9 & 21,0 & 19,8 & 19,7 \\
\hline 1 & 22,9 & 8,5 & 30,2 & 13,2 & 25,2 \\
\hline 2 & 12,1 & 39,4 & 10,6 & 25,2 & 12,7 \\
\hline 3 & 9,8 & 45,9 & 10,3 & 23,3 & 10,7 \\
\hline
\end{tabular}

The Vickers's hardness of as-consolidated nanostructured equiatomic $\mathrm{AlCuNiFeCr} \mathrm{HEA}$ has been found to be $9.2 \pm 0.25 \mathrm{GPa}$. The Young modulus of the HEA is $148 \pm 7 \mathrm{GPa}$. The high hardness could be attributed to the nanocrystalline nature of the alloy, the solid solution strengthening equiatomic nature of the phases and the presence of three-phase structure $[3,4,7]$. These AlCuNiFeCr HEA should also have good wear resistance according to the conclusion, that is, the wear resistance of materials is in general proportional to their Vickers hardness.

\section{CONCLUSIONS}

Mechanical alloying has been employed to synthesize nanocrystalline equiatomic $\mathrm{AlCuNiFeCr} \mathrm{HEA}$ consisting of supersaturated substitutional solid solutions with bcc crystal structure. High mixing entropy decreases free Gibbs energy of equiatomic alloy, reducing the tendency to ordering and segregation, facilitates the formation of a solid solution, and increases its stability compared to intermetallics and other ordered phases.

After sintering at $5 \mathrm{GPa}$ and $800^{\circ} \mathrm{C}$ for $0.5 \mathrm{~h}$, the alloy becomes three-phase and consist of a bcc solid solution matrix with fine precipitates (to $5 \%$ ) of two fcc solid solutions with different lattice parameters.

After pressure sintering, the $\mathrm{AlCuNiFeCr} \mathrm{HEA}$ has high hardness due to solid-solution hardening and strong lattice distortion resulting from different atomic radii of 
NAP-2018, 2018 IEEE 8th International Conference on "Nanomaterials: Applications \& Properties"

substitutional elements, nanostructured state, prevailing bcc phase, and a small content of two FCC phases.

\section{Acknowledgment}

The authors are thankful to Dr. A.A. Scheretskiy for the help with experiments.

\section{References}

[1] B. Cantor, I.T.H. Chang, P. Knight, A.J.B. Vincent, "Microstructural development in equiatomic multicomponent alloys", Mater. Sci. Eng. A, vol. 375-377, pp. 213-218, July 2004.

[2] J.-W. Yeh, S.-K. Chen, S.-J. Lin, and et. al., "Nanostructured highentropy alloys with multiple principal elements: Novel alloy design concepts and outcomes", Adv. Eng. Mater., vol. 6, pp. 299-303, May 2004.
[3] High-Entropy Alloys. Fundamentals and Applications. Editors M. C. Gao , J.-W. Yeh, P. K. Liaw, Y. Zhang. Elsevier, 2015, 516 p..

[4] B.S. Murty, J.W. Yeh and S. Ranganathan. High-Entropy Alloys. Elsevier, 2014, 218 p.

[5] C. Suryanarayana, "Mechanical alloying and milling", Prog. Mater. Sci., vol. 46, pp. 1-184, January 2001.

[6] W.C. Oliver and G.M. Pharr, "An improved technique for determining hardness and elastic modulus using load and displacement sensing indentation experiments," J. Mater. Res., vol. 7, pp. 1564-1583, June 1992.

[7] J.-W. Yeh, J., S.Y. Chang, Y.D. Hong and et. al., "Anomalous decrease in $\mathrm{X}$-ray diffraction intensities of $\mathrm{Cu}-\mathrm{Ni}-\mathrm{Al}-\mathrm{Co}-\mathrm{Cr}-\mathrm{Fe}-\mathrm{Si}$ alloy systems with multi-principal elements", Mater. Chem. Phys., vol. 103, pp. 41-46, May 2007.

[8] K.B. Zhang, Z.Y. Fu, J.Y. Zhang, et al., "Nanocrystalline $\mathrm{CoCrFeNiCuAl}$ high-entropy solid solution synthesized by mechanical alloying", .J Alloys Compd, vol. 485, pp. L31-34, October 2009. 